Anuario del Instituto de Historia Argentina, vol. 17, nº 2, e059, diciembre 2017.

ISSN 2314-257X

Universidad Nacional de La Plata.

Facultad de Humanidades y Ciencias de la Educación.

Centro de Historia Argentina y Americana

\title{
Ceruso, Diego, La izquierda en la fábrica. La militancia en el lugar de trabajo, 1916-1943. Buenos Aires: Imago Mundi, 2015, 320 pp.
}

\section{Felipe Venero}

Instituto de Investigaciones en Humanidades y Ciencias Sociales (UNLP - CONICET). Facultad de Humanidades y Ciencias de la Educación. Universidad Nacional de La Plata Argentina | venerof@gmail.com

\section{PALABRAS CLAVE}

Trabajadores

Sindicalismo de base

Izquierda

Movimiento obrero

\section{KEYWORDS}

Workers

Shop floor organization

Left movements

Labor Movement

\section{RESUMEN}

Este trabajo se propone realizar una lectura crítica del libro La izquierda en la fábrica. La militancia en el lugar de trabajo, 1916-1943, publicado por Diego Ceruso. El trabajo investiga el surgimiento de la organización sindical en el lugar de trabajo en argentina entre 1916 y 1943. Pone en cuestión un conjunto de hipótesis hegemónicas sobre el proceso y sostiene sus hipótesis con un enorme corpus documental. Nos proponemos ofrecer una mirada sobre el trabajo que incite a su lectura señalando los puntos acertados como ciertas debilidades que observamos.

\section{ABSTRACT}

This paper intends to make a critical reading of the book The left in the factory. The militancy in the workplace, 1916-1943, published by Diego Ceruso. The work investigates the emergence of shop floor organization in Argentina between 1916 and 1943. It calls into question a set of hegemonic hypotheses about the process and supports its hypotheses with a huge documentary corpus. We intend to offer a look at the work that encourages its reading by pointing out the correct points as certain weaknesses that we observe. 
Los estudios sobre el sindicalismo de base han crecido significativamente en los últimos años. Durante un largo tiempo, el conocimiento que teníamos sobre el tema se reducía a un conjunto de estudios clásicos cuyas hipótesis no eran objeto de controversias. Este renovado interés se asocia a la reactivación que se produjo en la organización en el lugar de trabajo en los últimos años y que reanimó la preocupación por comprender distintas dimensiones del fenómeno.

En este contexto debemos situar la publicación de La izquierda en la fábrica. La militancia en el lugar de trabajo, 1916-1943. El libro es el resultado directo de la tesis doctoral de Diego Ceruso y la cristalización de una larga investigación, de la que ya tuvimos un avance significativo con la aparición de su tesis de grado (Ceruso, 2010). La continuidad del objeto de estudio entre ambas publicaciones se ve enriquecida por una extensión del marco temporal examinado, con la ampliación del espectro sindical observada, con el notorio incremento de las fuentes abordadas y con una mirada más amplia en cuanto a la militancia de izquierda.

El libro está organizado en ocho capítulos divididos a partir de la periodización propuesta para el análisis. En cada apartado el autor expone una serie de elementos claves para entender la coyuntura: el constante desarrollo del aparato industrial que pone de manifiesto el crecimiento cuantitativo del asalariado fabril y la política de los distintos gobiernos en relación a los trabajadores. Pero son las transformaciones que se produjeron en el seno de las organizaciones del movimiento obrero, en la izquierda y los vínculos entre ambas, los hilos que anudan el relato. Progresivamente, el libro dará cuenta del desarrollo conjunto que tuvieron las organizaciones de izquierda y el movimiento obrero en este período.

Los dos primeros capítulos analizan el espacio de tiempo entre 1916 y 1928 en que comienza a vislumbrarse una organización en el lugar de trabajo, señalando la existencia de un panorama industrial y proletario en Buenos Aires para la época. Hacia fines de la década del diez Ceruso afirma que se produjo un novedad cualitativa con el gran dinamismo en la organización y confrontación en los gremios industriales, pese a que el sector de transportes era el de mayor relevancia. En este período surgen diversas formas organizativas en los lugares de trabajo: desde consejos hasta una gran cantidad de delegados de fábricas o de sección, pero con un alto grado de dispersión y sin un poder realmente significativo. Una momento clave es la adopción por parte del Partido Comunista de una estructura celular en 1924 que condujo a un fomento del desarrollo de las células fabriles.

El siguiente acápite pone de manifiesto el modo en que proliferaron las organizaciones de base entre 1928 y 1932, principalmente en el sector textil. Muchas células del PC se convirtieron en organizaciones más amplias en esos años, incorporando a trabajadores no comunistas, y los empresarios comenzaron a cuestionarlas con mayor énfasis. La estrategia de clase contra clase adoptada en 1928 se vio favorecida por la inserción partidaria producto de ese trabajo celular. Pero a la vez, los comités de fábrica comenzaron a mutar tomando distancia del partido y fortaleciendo sus lazos con la estructura sindical. Sus características tendieron a homogeneizarse: surgían en el lugar de trabajo, eran elegidas por los trabajadores y su principal preocupación eran las condiciones de trabajo. Este incremento en la organización de base se dio en el marco de creación de la CGT.

Los capítulos cuatro y cinco se enfocan en el período de recuperación económica posterior a la crisis (1932-37), en el que se registra un elevado nivel de actividad gremial. Los debates en torno a 
la prescindencia política en los gremios, que devino en la ruptura de la central obrera y el lento declive de la corriente sindicalista, marcaron el clima de la época. Interesa destacar que un sector del anarquismo leyó los cambios que se estaban produciendo, modificó su estrategia y llamó a la creación de comités. La huelga de la construcción de 1935 y la huelga general del año siguiente fueron dos hitos claves en el período y señalan la importancia de estas estructuras para el sostenimiento del conflicto aunque no tuvieran un rol organizativo activo como comités de huelga.

El sexto acápite marca el salto cualitativo en la participación de las comisiones internas en los conflictos en el bienio 1937-39, favorecido por la homogeneización que estas instancias asumieron anteriormente. El cambio se hizo notar en la huelga de albañiles de 1937 en la que los comités de obra sí adoptaron la forma de comités de huelga. El recorte temporal del siguiente capítulo (193941) se ajusta a los efectos que tuvo el inició de la segunda guerra mundial en la militancia sindical, principalmente el neutralismo adoptado por los comunistas a partir del pacto ruso-germano que le valió no pocas tensiones en el mundo obrero.

El último apartado avanza sobre el periodo 1941-43 en el que el PC abandona la neutralidad y se recrudecen los debates al interior de la CGT sobre la autonomía política: una alianza del comunismo con los socialistas que rechazaban la prescindencia les permitió hacerse de la central y condujo a una nueva ruptura. Un dato clave en este período es la pérdida de peso relativo que tuvieron los gremios vinculados al transporte y que favoreció al sector industrial. Una hipótesis central es que el sindicalismo de masas, concepto tomado de Collinet, ya estaría presente en esta etapa y no sería un resultado del peronismo. Central para entender este punto es el proceso de verticalización en el que se adentraron los comités de obra y de empresa, y que los condujo a una fuerte institucionalización.

Una mirada global le permite afirmar que el proceso de organización en el lugar de trabajo no fue uniforme, en tanto los trabajadores adoptaron distintos tipos de formas organizativas, que tendieron a homogeneizarse en su propio desarrollo, predominando la figura individual del delegado en los pequeños y medianos establecimientos y las comisiones internas en los grandes.

El libro se destaca sobre el conjunto de las investigaciones recientes sobre el sindicalismo de base por su cuestionamiento a las hipótesis centrales de los trabajos de Doyon (1984) y James (1981)realizando un aporte clave para el conocimiento sobre el tema. Ambos autores sostuvieron que comisiones internas y cuerpos de delegados se constituyeron durante el peronismo y que, por tanto, fueron un resultado del modelo sindical surgido en esa coyuntura. Más enfáticamente, Doyon afirma que las formas de organización en el lugar de trabajo previas a 1946 tuvieron una serie de particularidades que las diferenciarían: su escasa difusión y penetración, el no ser estructuras vinculadas al sindicato y, en muchos casos, ser creaciones patronales para contener el accionar de los trabajadores.

Frente a esta lectura, Ceruso comprueba que su origen se sitúa varios años antes del surgimiento del peronismo. Ya para 1916 encuentra evidencias dispersas de una incipiente organización en el lugar de trabajo que irá adquiriendo diversas formas con el correr de los años, pero que tendrá un camino ascendente a lo largo del período analizado. De este modo hace valer la hipótesis de que si bien durante el gobierno peronista el sindicalismo de base tuvo un enorme desarrollo, hizo pie en una 
estructura que tenía ya una larga trayectoria.

Un punto fuerte del libro es dar cuenta como el surgimiento de este tipo de organizaciones fue uno de los ejes de las transformaciones sufridas en el mundo sindical en el período. Estas transformaciones estuvieron atravesadas por un cambio fundamental en la estructura económica, como fue el surgimiento de la producción de tipo industrial, focalizada en las ciudades, principalmente en la Capital Federal y sus alrededores. Por esta razón es acertada la elección metodológica de exponer los lineamientos centrales del desarrollo industrial en cada etapa. Esta transformación fue dejando obsoletas la organización por oficio y favoreció el surgimiento del sindicato por rama. Analíticamente, este punto parece marcar un freno en relación al primer trabajo del autor, en el que se hacía especial énfasis en el vínculo entre la forma industrial y la organización sindical, y que aquí no se profundiza.

Uno de los argumentos que anudan gran parte del relato es la demostración del proceso de integración al sindicato que fueron teniendo las instancias de organización en el lugar de trabajo y que les valió perdida de autonomía y un mayor respeto a la verticalidad gremial.

Si uno de los puntos fuertes de la investigación es el enorme corpus documental con el que defiende sus hipótesis principales, en términos analíticos el libro pierde fuerza en el plano narrativo a la hora de articular los distintos planos observados. La organización interna de los capítulos fracciona elementos que ganarían potencialidad analítica al articularse de conjunto, si bien no es una tarea sencilla, otorgaría un salto significativo. La situación política nacional, el desarrollo industrial, las disputas en las corrientes políticas, quedan expuestas en su parcialidad y en el relato sólo se cruzan con la organización en el lugar de trabajo en cuanto a las grandes tendencias que señalan. De este modo, en muchos pasajes nos encontramos con que la necesidad del autor por exponer las pruebas no se traduce en un análisis más articulado de los procesos que describe.

En el mismo sentido observamos las tres referencias teóricas expuestas. La utilización del concepto de repertorios de organización, tomado de Charles Tilly, es la menos conflictiva en tanto es evidente su orientación para dar cuenta de un proceso que no siguió un patrón único. No obstante es válido señalar el aprovechamiento de un concepto que en general ha sido rechazado por el marxismo, pero que puede ser de utilidad en este tipo de estudios. La caracterización del fenómeno a partir de Collinet como sindicalismo de masas es un salto en relación a la idea de sindicalismo moderno o de nuevo tipo que se encontraba en su tesis de licenciatura. El autor francés entiende que una de las características medulares de este tipo de sindicalismo es una fuerte institucionalización al interior del sindicato, en la que las decisiones dirigenciales cobran mayor peso que las de los militantes. La importancia de este aspecto se debe a que es una característica que la literatura específica siempre asoció al peronismo y que Ceruso observa en los años previos. En este sentido sorprende que de cuenta del problema solo en el caso de los obreros de la construcción y que no sirva para analizar al conjunto del movimiento obrero.

Una de las referencias teóricas de las que parte la investigación es la clásica caracterización de gramsciana en torno al surgimiento de la hegemonía en el lugar de trabajo mismo y, del mismo modo, al hecho de que el proceso revolucionario emerge allí mismo. Este enfoque habilitaría la importancia de estudiar la organización en el lugar de trabajo. Nos parece relevante señalar un 
problema fundamental en esta elección y que excede al trabajo reseñado, ya que se percibe en el conjunto de los estudios sobre el sindicalismo de base. Estos estudios se enfocan en las formas organizativas generadas por los trabajadores, desatendiendo la dimensión inicial del planteo de Gramsci en cuanto a la construcción de hegemónica, edificando una mirada sobre el sindicalismo de base que no aporta elementos contundentes a la comprensión de la dominación capitalista.

Ninguna de las objeciones apuntas pone en juego el valor del libro para refrescar las miradas hegemónicas sobre el tema. En cuanto al proceso de investigación, Ceruso logra sostener las hipótesis propuestas de manera contundente. La izquierda en la fábrica es un insumo clave para la comprensión de la formación del movimiento obrero en nuestro país y del rol jugado por las organizaciones de izquierda en ese proceso.

\section{Bibliografía}

Ceruso, D. (2010). Comisiones internas de fábrica. Desde la huelga de la construcción de 1935 hasta el golpe de estado de 1943. Vicente López: PIMSA y Dialektik.

Doyon, L. (1984). La organización del movimiento sindical peronista, 1946-1955. Desarrollo Económico ( $n^{\circ}$ 94). Buenos Aires: IDAES.

James, D. (1981). Racionalización y respuesta de la clase obrera: contexto y limitaciones de la actividad gremial en la Argentina. Desarrollo Económico ( $n^{\circ}$ 83). Buenos Aires: IDAES. 